\title{
Ataxias Espinocerebelares
}

Hélio A. G. Teive*

\section{RESUMO}

O autor apresenta uma revisão sobre as ataxias hereditárias autossômicas dominantes, agora definidas como ataxias espinocerebelares, enfatizando os diferentes tipos, dentro de uma classificação clínico-genética.

\section{UNITERMOS}

Ataxias hereditárias, ataxia espinocerebelar, locus genético.
Professor Assistente de Neurologia - UFPR. Coodenador da Residência de Neurologia e do Ambulatório de Distúrbios do Movimento-Hospital de Clínicas - UFPR. Presidente da Sociedade Paranaense de Ciências Neurológicas.

\section{INTRODUÇÃO}

As ataxias hereditárias apresentam uma prevalência entre 1.5 e 22.1 por 100.000 pessoas em diferentes estudos publicados. Kurtzke e Kurland, em 1992, encontraram uma média de 8 casos para cada 100.000 habitantes em populações brancas do Ocidente. Outros estudos definem a prevalência de casos familiares das ataxias espinocerebelares de aproximadamente 1 por 100.000. Existem regiões do mundo em que a prevalência das ataxias hereditárias é bem maior, como por exemplo, em Cuba (Holguin-Tacajó), nos Açores (em especial na ilha das Flores), na Rússia (Sibéria), nos Estados Unidos da América (Massachussets e na Califórnia), na Espanha (Cantábria), e na Noruega ${ }^{3,10,24}$.

No Brasil, Cassa $^{3}$ realizou o único estudo epidemiológico que avaliou a prevalência das ataxias hereditárias, particularmente das autossômicas dominantes (incluindo a doença de Machado-Joseph), observando uma prevalência média de 6.55 casos por 100.000 habitantes (com variações de 0.79 a 228 ), nos estados de Minas Gerais, São Paulo, Goiás e Espírito Santo.

Na região sul do Brasil, particularmente na região da costa litorânea do estado de Santa Catarina, tem-se observado, ainda sem estudos epidemiológicos realizados, uma grande prevalência de famílias com ataxias hereditárias, predominantemente autossômicas dominantes ${ }^{18,19,26,27}$.

\section{CLASSIFICAÇÃO DAS ATAXIAS HEREDITÁRIAS - HISTÓRICO}

Várias classificações já foram propostas para as ataxias hereditárias, incluindo a de Holmes (que dividia as ataxias em: 1. de início precoce: ataxia de Friedreich e 2. de início tardio: ataxia de Marie), de Greenfield, a de Konigsmark e Weiner, a de Barbeau e colaboradores, a classificação da Federação Mundial de Neurologia, da Organização Mundial de Saúde, a de Currier e Subramony e finalmente a de Harding. Todas têm a idéia fundamental de tentar organizar e definir este grupo vasto e complexo de enfermidades neurodegenerativas, que apresentam como principal 
componente a ataxia. Entre as mais conhecidas está sem dúvida a classificação proposta pela professora Anita Harding, que está resumida na tabela $1^{9,10}$.

\section{TABELA 1}

Classificação das ataxias hereditárias e paraplegias Anita E. Harding, $1984^{10}$

I. Desordens congênitas de etiologia desconhecida

II. Desordens atáxicas com defeito metabólico conhecido ou outras causas

Desordens metabólicas

Desordens por defeito de reparação do DNA

Ataxia telangiectásica

III. Desordens atáxicas de etiologia desconhecida

Ataxia cerebelar de início precoce $(<20$ anos)

Ataxia de Friedreich

Ataxia cerebelar de início tardio (>20 anos)

Ataxia cerebelar autossômica dominante (ACAD)

Tipo 1 (com atrofia óptica/ oftalmoplegia/demência/sinais extrapiramidais/amiotrofia)

Tipo 2 (com degeneração de retina)

Tipo 3 (forma "pura")

Tipo 4 (com mioclonia e surdez)

Ataxia autossômica dominante periódica

IV. Paraplegia espástica hereditária

Papaplegia espástica "pura"

Paraplegia espástica complicada

Em primeiro lugar a classificação de Harding separa as ataxias cerebelares de início precoce (antes dos 20 anos), que incluem a ataxia de Friedreich, as ataxias congênitas, associadas a distúrbios metabólicos e a defeitos de reparação do DNA, como a ataxia telangiectásica, e as ataxias cerebelares de início tardio, que incluem as chamadas ataxias cerebelares autossômicas dominantes (ACAD). As ACAD são subdivididas, segundo Harding, nos tipos 1, 2, 3 e 4 . O tipo 1 caracteriza-se por apresentar atrofia óptica, oftalmoplegia, demência, amiotrofia e sinais extrapiramidais. O tipo 2 apresenta degeneração de retina, podendo associar-se à oftalmoplegia e sinais extrapiramidais, e o tipo 3 seria uma forma de ataxia cerebelar "pura", enquanto que o tipo 4 associaria-se com surdez e mioclonia ${ }^{10}$.

Evidentemente, em face da grande heterogeneidade clínica e também anatomopatológica das diferentes ataxias hereditárias, todas as classificações possuem problemas de aplicabilidade prática e não apresentam um consenso geral.

$\mathrm{Na}$ atualidade, com o fantástico avanço das técnicas de genética molecular, com o uso do PCR (técnica da reação de cadeia em polimerase), vários locus de gens têm sido descobertos, em diferentes cromossomas, permitindo desta forma a utilização de uma classificação mais racional, definida como classificação clínicogenética.

A tabela 2 resume as principais ataxias hereditárias (recessivas e dominantes, além das ligadas ao $\mathrm{X}$ e as mitocondriais) já conhecidas até o momento ${ }^{2,9,24}$.

\section{TABELA 2}

\section{Classificação atual das ataxias hereditárias}

1. Ataxias autossômicas recessivas Ataxia de Friedreich: Cromossoma 9

Ataxia com deficiência seletiva de vitamina E: Cromossoma 8

Ataxia telangiectásica: Cromossoma 11

Ataxia associada: A mioclonia: Cromossoma 21

Hipogonadismo

Ataxia recessiva de início no adulto

2. Ataxias autossômicas dominantes

Ataxia espinocerebelar: Tipo 1, 2, 3, 4, 5, 6, 7, 8

Atrofia dentatorubropalidoluysiana

Ataxias periódicas: Tipos 1 e 2

3. Ataxias ligadas ao $\mathrm{X}$

4. Ataxias mitocondriais

\section{DISCUSSÃO}

No presente artigo vai ser abordado unicamente o grupo das ataxias cerebelares autossômicas dominantes, agora definidas como ataxias espinocerebelares (AEC).

As AEC representam um grupo expressivo de entidades, algumas delas com uma grande prevalência populacional em diferentes partes do mundo, como por exemplo a doença de Machado-Joseph (DMJ).

Pode-se definir como características peculiares a este grupo de AEC, os seguintes fatores: 
1. Herança autossômica dominante: ou seja, existem pacientes afetados em todas as gerações, com indistinção de sexo e com uma média de acometimento dos descendentes de um paciente afetado em torno de $50 \%$.

2. Presença de ataxia cerebelar, predominante de marcha, com início após a vida adulta (acima dos 20 anos), que pode acompanhar-se de diferentes outras manifestações, como por exemplo: oftalmoplegia, nistagmo, movimentos sacádicos lentos, atrofia óptica, degeneração de retina, fasciculações da face e da língua, mioquimia facial, distonia, parkinsonismo, coréia, espasticidade e sinais piramidais, disfunção cognitiva, amiotrofia e sinais de neuropatia periférica, neuronopatia sensitiva, retração palpebral, com "bulging eyes", entre outros.

3. A origem étnica do paciente eventualmente pode auxiliar na investigação das diferentes AEC, como por exemplo, a descendência portuguesa-açoriana, na doença de Machado-Joseph, a espanhola (na AEC do tipo 2), a italiana (na AEC do tipo 1), a japonesa (na atrofia dentatorubropálidoluysiana).

4. Os exames de neuroimagem, particularmente ressonância magnética, podem demonstrar a presença de atrofia do cerebelo, da ponte, eventualmente das olivas, ou mesmo do tronco encefálico, em graus variados. Os achados de neuroimagem, contudo, não permitem uma correta diferenciação nosológica entre as diferentes AEC.

5. O estudo anatomopatológico também não permite, na maioria das vezes, um diagnóstico nosológico adequado entre as diversas AEC.

6. Não há até o momento tratamentos definidos para os diferentes grupos de AEC, existindo entretanto inúmeros relatos de testes terapêuticos, com medicações colinérgicas, serotoninérgicas, gabaérgicas e também dopaminérgicas.

7. Algumas das principais AEC já definidas geneticamente apresentam como carcaterística em comum a presença de mutações com um trinucleotídeo (CAG) repetido, expandido, e instável, na região codificada do gene específico. Esta característica é peculiar também a outras enfermidades neurológicas conhecidas como a doença de Huntington, a distrofia miotônica e a síndrome de Kennedy (atrofia muscular bulboespinhal). Interroga-se que o produto protéico oriundo da mutação, com a presença de tratos de poliglutamina, produziria um ganho de função e subseqüentemente levaria a uma degeneração neuronal específica. Um dos aspectos de grande importância nestas doenças que apresentam um
CAG expandido é o fenômeno da antecipação genética, ou seja, pode ocorrer um aumento da severidade da doença e início de sintomas mais precocemente em gerações sucessivas, decorrente de um aumento do número de repetições do trinucleotídeo expandido. A antecipação é freqüentemente maior inclusive com a transmissão paterna, do que com a materna, por razões ainda desconhecidas ${ }^{1,2,3,5,6,9,12,14,24}$.

Uma das grandes dificuldades para o estudo das AEC é a heterogeneidade fenotípica e genotípica. A heterogeneidade fenotípica implica que o mesmo genótipo pode determinar vários fenótipos e a heterogeneidade genotípica determina que o mesmo fenótipo pode ser decorrente de vários genó$\operatorname{tipos}^{2,5,9,22,23,24}$.

A classificação mais recente das ataxias cerebelares hereditárias do tipo autossômicas dominantes, agora definidas como ataxia espinocerebelar (AEC), está resumida na tabela 3 :

TABELA 3

Ataxias autossômicas dominantes - AEC

Ataxia espinocerebelar tipo 1 - AEC 1: Cromossoma 6

Ataxia espinocerebelar tipo 2 - AEC 2: Cromossoma 12

Ataxia espinocerebelar tipo 3-AEC 3: Doença de: Machado-Joseph - DMJ: Cromossoma 14

Ataxia espinocerebelar tipo 4-AEC 4: Cromossoma 16

Ataxia espinocerebelar tipo 5 - AEC 5: Cromossoma 11

Ataxia espinocerebelar tipo 6 - AEC 6: Cromossoma 19

Ataxia espinocerebelar tipo 7 - AEC 7: Cromossoma 3

Ataxia espinocerebelar tipo 8-AEC 8: Cromossoma 10

Atrofia dentatorubropalidoluysiana - ADRPL: Cromossoma 12

Ataxias paroxísticas:

Com mioquimia: Cromossoma 12

Com nistagmo: Cromossoma 19

Apesar das diferenças clínicas muitas vezes observadas nos diferentes tipos de AEC, o diagnóstico através dos estudos de genética molecular faz-se mister, em face da grande heterogeneidade fenotípica (genótipo 
único e fenótipo variável) e genotípica (fenótipo único com genótipos diversos).

Discutiremos a seguir as principais AEC até agora conhecidas, salientando-se que periodicamente, em face do avanço expressivo da área de genética molecular, novos genes são definidos e novas entidades surgem conseqüentemente.

\section{ATAXIA ESPINOCEREBELAR DO TIPO 1 (AEC 1)}

Esta forma de ataxia cerebelar hereditária autossômica dominante tem sido encontrada em diferentes grunos étnicos (particularmente os de origem italiana), costuma iniciar-se após os 20 anos de idade e apresenta quadro de desequilíbrio de marcha, com ataxia mais severa da marcha que dos membros, disartria, nistagmo, hiperreflexia profunda (podendo associar-se à arreflexia profunda distal, na evolução do quadro), oftalmoparesia e lentificação dos movimentos sacádicos. Pode associar-se paralisia bulbar, disfunção cognitiva e distonia.

Do ponto de vista anatomopatológico os sistemas mais envolvidos são o cerebelo (perda das células de Purkinje e do núcleo denteado), a ponte, o pedúnculo cerebelar médio e as olivas.

A doença foi mapeada no cromossoma 6 (6p 22-23), e a mutação genética definida como uma expansão instável de uma sequiência de CAG repetida (geralmente entre 41-81 repetições).

Os números de CAG repetidos correlacionam-se com a idade de início do quadro, bem como com a duração da doença. Alguns autores têm encontrado relação entre ò padrão de transmissão (por exemplo paterna) e um maior aumento do número de CAG repetido, e também com o fenômeno da antecipação da doença.

Nas diferentes séries mundiais de ataxias cerebelares hereditárias autossômicas dominantes, a AEC do tipo 1 tem sido detectada numa prevalência variável de 4 a $19 \%$ dos casos. Entretanto, algumas séries publicadas já encontraram uma frequiência bem maior de até $50 \%$ dos seus $\operatorname{casos}^{9,13,23,24}$.

Teive e colaboradores, em um estudo recente (ainda não-publicado), de 30 famílias com AEC, oriundas dos estados de Santa Catarina (21 famílias), do Paraná (8 famílias) e do Mato Grosso do Sul (1 família), encontraram a mutação da AEC do tipo $1 \mathrm{em}$ apenas 2 famílias $(6,6 \%)$, uma de origem italiana e outra de origem portuguesa.

\section{ATAXIA ESPINOCEREBELAR DO TIPO 2 (AEC 2)}

A AEC do tipo 2 é caracterizada por apresentar ataxia cerebelar associada à disartria, tremores, hipo/arreflexia profunda nos membros superiores e também nos inferiores (definindo a presença de neuropatia periférica), fasciculações de face e de membros, e caracteristicamente pela presença de movimentos oculares sacádicos lentos.

A doença foi originalmente descrita na Índia, por Wadia e Swami, em 1971, e posteriormente bastante estudada em Cuba (Holguin), por Orozco Diaz, em $1990^{17,28}$.

Neuropatologicamente a AEC do tipo II é caracterizada por atrofia cerebelar, com perda das células de Purkinje e células granulares, perda de neurônios olivares, da substância negra e células do corno anterior da medula espinhal.

O locus da AEC do tipo 2 está localizado no cromossoma 12 , na posição 12 q 23-24.1, e recentemente foi descoberta a mutação genética responsável.

$\mathrm{O}$ estudos genéticos atuais sugerem que esta forma de ataxia hereditária não seja um tipo muito comum, contudo pela recente descoberta da mutação genética, ainda não ocorreu uma real análise da prevalência desta enfermidade entre as ataxias hereditárias dominantes. No continente americano há de se ressaltar a grande prevalência desta entidade na ilha de Cuba, na província de Holguin, caracterizando-se principalmente pela associação de ataxia cerebelar, com atrofia do cerebelo nos exames de neuroimagem, associado à presença de neuropatia periférica e de movimentos oculares sacádicos lentos ${ }^{9,17,24,28}$.

Em nossa casuística (dados ainda não-publicados) de um total de 30 famílias com AEC, já estudadas do ponto de vista de genética molecular, apenas uma família apresenta a mutação da AEC tipo 2.

\section{ATAXIA ESPINOCEREBELAR DO TIPO 3 (AEC 3) - DOENÇA DE MACHADO-JOSEPH}

A doença de Machado-Joseph (DMJ) foi originalmente descrita entre descendentes portuguesesaçorianos, radicados nos Estados Unidos da América do Norte, no período de 1972-1976, através dos trabalhos publicados por Nakano e colaboradores (doença de Machado, descrita em descendentes de emigrantes portugueses - família Machado, radicados 
em Massachussets/EUA), Woods e Schaumburg (degeneração nigro-espino-dentata, com oftalmoplegia nuclear, descrita na família Thomas, de origem açoriana) e Rosemberg e colaboradores (degeneração estriatonigral autossômica dominante, descrita na família Joseph, na verdade nos descendentes de José (Joseph) Bastiana, originário dos Açores) ${ }^{15,21,30}$.

Posteriormente, a doença foi melhor classificada através dos estudos de Romanul e colaboradores, Barbeau e colaboradores e principalmente pelos estudos de Coutinho e colaboradores, entre outros ${ }^{1,4,7,8,20}$.

A enfermidade apresenta, de maneira variável, ataxia cerebelar, associada a sinais piramidais, amiotrofia periférica, fasciculações de face, língua e membros, distonia, parkinsonismo, oftalmoparesia e retração palpebral ("bulging eyes").

Do ponto de vista neuropatológico ocorre perda de células da substância negra, núcleo rubro, núcleos pontinos e dos nervos motores cranianos, núcleo denteado do cerebelo, cornos anteriores da medula espinhal, podendo acometer o globo pálido e o núcleo rubro. Não é comum o comprometimento das olivas bulbares e do córtex cerebelar e cerebral $^{1,4,5,6,7,8,9,10,14,15,20,21,25,30}$.

O locus genético da DMJ foi mapeado no braço longo do cromossoma 14, na posição 14 q 24.3-q32 e a mutação identificada como uma expansão repetida de CAG, instável. O número de CAG repetido na DMJ tem variado entre $66-84^{2,3,9,11,12,22,23,24}$.

Stevanin e colaboradores, em 1994, publicaram uma série de pacientes (de origem não-portuguesa-açoriana) com ataxia espinocerebelar, chamada de AEC do tipo 3 , localizada no cromossoma 14 , com mutação definida, junto à da DMJ, mas que os autores definiam como fenotipicamente diferente da DMJ (ausência de distonia, fasciculações faciolinguais e de "bulging eyes").

$\mathrm{Na}$ classificação da AEC persistiu a terminologia AEC do tipo 3 / DMJ, colocando as duas entidades na mesma posição da classificação, mas separadas fenotipicamente. Matilla e colaboradores, em 1995, definiram claramente que as duas entidades representam na verdade a mesma doença, com a mesma mutação, apenas com variações fenotípicas ${ }^{9,11,12,24}$.

Os mecanismos responsáveis pela variação fenotípica que ocorre na $\mathrm{AEC}$ do tipo III, ou seja, na DMJ, são variados, sendo as seguintes possibilidades consideradas: 1. o número de repetições dos trinucleotídeos (maior número, com início mais precoce e severo), 2. as características do alelo normal, quanto ao número de repetições do trinucleotídeo, 3. o fenômeno do "imprinting" (transmissão paternal ou maternal), 4. mosaicismo somático (diferenças entre os número de
CAG repetidos nos diferentes tecidos), 5. o papel dos genes modificadores, 6 . o polimorfismo do alelo afetado (diferentes códons), 7. fatores ambientais, 8. presença de homozigosidade ${ }^{12}$.

A DMJ tem sido classificada em 3 tipos diferentes: a) Tipo 1: caracterizada pela presença de síndrome piramidal, associado a extrapiramidal (distonia, rigidez parkinsoniana), e oftalmoplegia externa progressiva; b) Tipo 2: caracterizada pela presença de síndrome cerebelar, associada à síndrome piramidal e c) Tipo 3: com síndrome cerebelar associada à amiotrofia periférica $^{5,14}$.

Posteriormente, 2 novos subtipos foram adicionados: d) Tipo 4: com síndrome parkinsoniana associada à neuropatia periférica (descrito por Rosemberg) e e) Tipo 5: com síndrome de paraplegia espástica (descrito por Sakai e colaboradores). Recentemente, Ishikawa e colaboradores descreveram também um caso de DMJ, geneticamente comprovado, com quadro clínico neurológico de ataxia cerebelar "pura" ", 12 .

Coutinho $^{6}$ apresentou durante o 3rd International Worshop on Machado-Joseph Disease, realizado em Furnas, São Miguel, nos Açores, em 1994, uma revisão acerca da variação da expressão clínica da DMJ com a progressão da doença e idade. Ela definiu que os sinais cerebelares e a oftalmoplegia podem aparecer em qualquer faixa etária, contudo os sinais piramidais e extrapiramidais tendem a ser menos freqüentes com a idade mais avançada, enquanto que os sinais de comprometimento periférico aumentam, quanto maior for a faixa etária dos pacientes. Outro aspecto a se considerar também é a possibilidade de variação fenotípica intrafamilial, definindo-se por vezes vários subtipos da doença na mesma família.

Em 1980, Lima e Coutinho propuseram os seguintes critérios diagnósticos para a DMJ:

- Herança autossômica dominante

- Sinais neurológicos maiores: ataxia cerebelar, sinais piramidais, extrapiramidais e amiotrofia.

- Sinais neurológicos menores: oftalmoplegia externa progressiva, distonia, fasciculações e "bulging eyes" 14 .

Em 1992, Paula Coutinho, em sua tese de doutorado, propõe os seguintes critérios diagnósticos para a DMJ:

- Transmissão autossômica dominante.

- Início na idade adulta.

- Presença de ataxia + oftalmoparesia supranuclear, sinais piramidais, extrapiramidais, acometimento do sistema nervoso periférico.

- Sinais menores: fasciculações + retração palpebral.

- Preservação das funções corticais superiores. 
- Sobrevida média de 21 anos 5 .

A DMJ, originalmente descrita em portuguêses de origem açoriana, tem sido cada vez mais descrita em diferentes etnias, como na japonesa, chinesa, negra, indiana, espanhola, francesa, alemã, italiana, judia, australiana, brasileira e por portugueses radicados nos EUA e no Canadá. Esta situação tem motivado uma acirrada discussão sobre a presença de uma mutação isolada na DMJ (founder mutation), com disseminação da doença pelos portugueses, na época das grandes navegações ou a presença de várias mutações em diferentes países ${ }^{2,3,9,11,12,22,23,24}$.

No Brasil a DMJ foi descrita inicialmente em uma família por Lisboa e Mariotto, em 1984, sem uma correta definição da doença e posteriormente por Radvany e colaboradores (em 1988). A primeira publicação sobre a DMJ em nosso meio ocorreu em 1990, por Teive e colaboradores $^{18,19,26,27}$.

Mais recentemente Cassa (1996) publicou uma série de 33 famílias com ataxia espinocerebelar, num total de 186 pacientes, tendo a DMJ como a forma mais comumente encontrada pelos estudos de genética molecular realizados $(10,8 \%)^{3}$.

Silveira e colaboradores, em 1995, publicaram uma grande série de pacientes com ataxia espinocerebelar, incluindo casos de AEC do tipo I, DMJ e ADRPL, e observaram que do total de 92 pacientes, $41 \%$ apresentavam mutação para a DMJ (84\% no grupo de pacientes de origem portuguesa e $17 \%$ no grupo de origem não-portuguesa) ${ }^{23}$.

Lopes-Cendes e colaboradores, em 1996, relataram 41 famílias brasileiras estudadas com AEC, das quais os estudos genéticos revelaram que $42,8 \%$ apresentavam a mutação para a DMJ (Trabalho apresentado como tema livre no Congresso Internacional de Genética Humana, Rio de Janeiro, agosto, 1996).

Teive e colaboradores, em 1996, estudando 50 famílias com ataxia cerebelar hereditária, 35 das quais com ataxia cerebelar autossômica dominante, e 20 delas com estudos genéticos completos, encontraram a DMJ em $40 \%$ dos casos, e AEC do tipo 1 em apenas $5 \%$ dos casos (Trabalho apresentado como Poster no XVII Congresso Brasileiro de Neurologia, Curitiba, Paraná, setembro, 1996).

Mais recentemente, Teive e colaboradores, estudando um grupo de 30 famílias com AEC, 27 delas de extração portuguesa-açoriana, detectaram apresença da mutação da DMJ (Centre for Research in Neuroscience-McGill University - Drs. Iscia Lopes-Cendes e Guy Roleau) em 14 famílias (46,6\%), caracterizando-a como a AEC mais comumente encontrada em nosso meio (dados ainda não-publicados).
Vários outros estudos em diferentes países (como o Japão, Alemanha, Portugal, China e Índia, por exemplo) têm demonstrado também que a DMJ é a forma de AEC mais freqüentemente encontrada através dos estudos de genética molecular ${ }^{11,12,22}$.

A grande discussão, hoje ainda existente, está fundamentada na valorização de critérios clínicos (ou seja, na presença de fenótipos sugestivos de cada AEC) e na confirmação das AEC pelos testes de genética molecular (por vezes definindo a AEC, sem que exista um fenótipo característico da doença do ponto de vista clínico).

Obviamente que o diagnóstico definitivo das AEC só pode ser feito através dos estudos de genética molecular, com a definição precisa do locus genético. Contudo, na avaliação dos pacientes com AEC, em especial na DMJ (que aparece nos principais estudos como a ataxia hereditária autossômica dominante mais encontrada no Brasil), existem determinados sinais neurológicos que podem sugerir o diagnóstico clínico, particularmente nos pacientes de extração portuguesa-açoriana. Em face do exposto pode-se propor os seguintes critérios diagnósticos para a DMJ (tabela 4):

\section{TABELA 4}

Critérios diagnósticos para a Doença de Machado-Joseph

1. DMJ Definida: Quando há confirmação pelo estudo de genética molecular:

$14 \mathrm{q} 24.3-32$

2. DMJ Provável: Quando se observa a presença dos critérios de P. Coutinho modificados:

- herança autossômica dominante,

- início na idade adulta,

- presença de ataxia + oftalmoparesia + sinais piramidais + distonia + parkinsonismo + amiotrofia,

- sinais menores: fasciculações facio-linguais + retração palpebral,

- ausência de demência,

- variação fenotípica intrafamiliar,

- etnia portuguesa-açoriana.

3. DMJ Possível: Qualquer ataxia hereditária com herança autossômica dominante definida. 


\section{ATAXIA ESPINOCEREBELAR DO TIPO 4 (AEC 4)}

A AEC do tipo IV é caracterizada por apresentar quadro de ataxia cerebelar associado à perda da sensibilidade, principalmente a profunda (neuronopatia sensitiva), sendo portanto uma ataxia mista.

O gene responsável foi localizado no cromossoma 16, em uma família originária de Utah/ EUA, por Gardner e colaboradores, mas ainda não foi realizada a sua identificação. Existem descrições prévias na literatura mundial sobre a doença com o uso do epônimo Ataxia de Biemond (1954: la forme radiculo-cordonnale postériure des dégénérescences spino-cérébelleuses). Nachamanoff e colaboradores publicaram em 1997 uma ataxia hereditária com neuronopatia sensitiva: ataxia de Biemond, com estudos de anatomia patológica demonstrando atrofia severa do cerebelo e da medula espinhal, em particular a coluna posterior, definindo como provável AEC do tipo IV ${ }^{16}$.

\section{ATAXIA ESPINOCEREBELAR DO TIPO 5 (AEC 5)}

A AEC do tipo 5 é basicamente uma forma de ataxia cerebelar "pura" de início tardio na vida adulta. Raramente associam-se ao quadro cerebelar (ataxia de marcha e disartria) sinais piramidais, oculomotores e bulbares.

Ranum e colaboradores, em 1994, descreveram a doença em uma família de descendentes do presidente americano A. Lincoln, realizando o mapeamento no cromossoma de número 11 , ainda sem identificação do gene.

Esta família apresenta um quadro bastante benigno de AEC, com predomínio de ataxia cerebelar e a presença de discretos sinais piramidais ${ }^{9,12,24}$.

\section{ATAXIA ESPINOCEREBELAR DO TIPO 6 (AEC 6)}

A AEC do tipo 6 foi inicialmente descrita como uma forma de ataxia hereditária que apresenta ataxia cerebelar associada à presença de demência e de sinais de disfunção do lobo frontal. Até recentemente (1996) nada estava definido sobre o cromossoma envolvido e o locus genético responsável.

Recentemente, Zhuchenko e colaboradores (1997) encontraram a presença da expansão de um CAG repetido no gene responsável pelo canal de cálcio, voltagem dependente, denominado alpha (1A), que foi mapeado no cromossoma 19p13. A partir daí definiuse esta entidade como AEC do tipo 6. O estudo foi realizado em 8 famílias, que apresentam um quadro de ataxia cerebelar lentamente progressivo, com leve acometimento da sensibilidade profunda (vibratória), com evolução de 20 a 30 anos para incapacitação em cadeira de rodas e óbito geralmente por broncoaspiração.

\section{ATAXIA ESPINOCEREBELAR DO TIPO 7 (AEC 7)}

A AEC do tipo 7 representa um grupo de famílias com ataxia cerebelar autossômica dominante, associado a quadro de perda visual progressiva por degeneração de retina. Podem-se associar sinais piramidais, oftalmoplegia, parkinsonismo e lentificação dos movimentos sacádicos.

Do ponto de vista neuropatológico, existe degeneração olivopontocerebelar associada à perda de células ganglionares da retina e a distrofia pigmentar da mácula.

Recentemente, o locus para este tipo de ataxia foi mapeado no cromossoma 3 e o locus genético definido (por Benomar e colaboradores, Gouw e colaboradores e por Holmberg e colaboradores) na posição 3p12-p21.1.

$\mathrm{O}$ quadro clínico pode aparecer desde a infância precoce até os 60 anos de idade, com uma progressão muito mais rápida quando do início mais precoce. O fenômeno da antecipação pode estar presente nestas famílias $^{2,9,12,24}$.

\section{ATAXIA ESPINOCEREBELAR DO TIPO 8 (AEC 8)}

Recentemente (1997), Nikali e colaboradores publicaram um estudo acerca de famílias finlandesas, que apresentavam um quadro de ataxia espinocerebelar de início precoce (início entre o primeiro e o segundo ano de vida), com ataxia, hipotonia, atetose, perda dos reflexos profundos, seguindo-se pela presença de oftalmoplegia e perda auditiva na idade escolar e, posteriormente, na adolescência, por neuropatia sensitiva e eventualmente epilepsia. O quadro foi definido como ataxia hereditária de início precoce (na infância), com neuropatia sensitiva (IOSCA- infantileonset spinocerebellar ataxia). 
O estudos de genética molecular definiram o locus da doença no cromossoma 10q23.3-24.1 e passaram a defini-la como AEC 8.

\section{ATROFIA DENTATORUBROPALIDOLUYSIANA (ADRPL)}

Esta enfermidade, que apresenta grande variabilidade fenotípica, descrita inicialmente com grande prevalência em japoneses, foi recentemente descrita em afroamericanos ("Haw River Syndrome") e europeus.

A mutação encontrada nesta doença está localizada no cromossoma 12 p e representa uma expansão de CAG instável (com repetições entre 54-75).

A doença apresenta quadro de ataxia cerebelar associado a 3 principais formas clínicas: com epilepsia mioclônica (associado à demência), com coreoatetose e demência (simulando a doença de Huntington) e com quadros de psicose, parkinsonismo e sinais piramidais.

A forma de ADRPL de início na juventude costuma apresentar-se com epilepsia e demência, ao passo que as formas de início mais tardio apresentam-se com ataxia, coréia e demência. Portanto, a ADRPL pode ser confundida com quadros de epilepsia mioclônica familiar, com a doença de Huntington e com as AEC, em particular a doença de Machado-Joseph.

Do ponto de vista neuropatológico, existe perda neuronal no núcleo denteado, rubro, no globo pálido e núcleo subtalâmico.

A idade de início da enfermidade é inversamente proporcional ao número de repetições do CAG.

Em face da multiplicidade de apresentação clínica da ADRPL, esta entidade é incluída entre as diferentes $\mathrm{AEC}$, s̀em definicão espeçífica com relação à classificàção clínico-genética ${ }^{29}$.

\section{ATAXIA CEREBELAR AUTOSSÔMICA DOMINANTE PAROXÍSTICA}

Existem 2 tipos de ataxia cerebelar autossômica dominante que apresentam ataques paroxísticos de ataxia.

O primeiro tipo (ACADP tipo 1) tem início na infância, está associado à presença de mioquimias, e tem ataques de ataxia que duram segundos a minutos (desencadeados por exercício e por "susto"). A doença está associada a uma mutação no cromossoma 12 (gene do canal de potássio- KCNA1) e responde ao tratamento com o uso de acetazolamida. A mioquimia aparece no

\begin{tabular}{|c|c|c|}
\hline \multicolumn{3}{|c|}{$\begin{array}{l}\text { TABELA } 5 \\
\text { cação clínico-genética resumida }\end{array}$} \\
\hline$A E C$ & Locus & Sinais Neurológicos Associados \\
\hline Tipo 1 & $6 \mathrm{p} 22-23$ & sinais piramidais, oftalmoplegia \\
\hline Tipo 2 & $12 q 23-24.1$ & $\begin{array}{l}\text { neuropatia periférica, mvto. } \\
\text { sacádico lento }\end{array}$ \\
\hline Tipo 3/DMJ & $14 q 24.3-32$ & $\begin{array}{l}\text { sinais piram-extrapiramidais, } \\
\text { amiotrofia, oftalmoplegia, } \\
\text { fasciculações, "bulging eyes" }\end{array}$ \\
\hline Tipo 4 & 16 & neuronopatia sensitiva \\
\hline Tipo 5 & 11 & forma "pura" \\
\hline Tipo 6 & 19 p $13 "$ & $\begin{array}{l}\text { demência, sinais frontais, } \\
\text { piramidais }\end{array}$ \\
\hline Tipo 7 & $3 p 12-21.1$ & perda visual progressiva \\
\hline Tipo 8 & $10 q 23.3-24.1$ & $\begin{array}{l}\text { neuronopatia sensitiva, início } \\
\text { infância }\end{array}$ \\
\hline ADRPL & $12 q$ & mioclonia, coréia, demência \\
\hline Parox.: 1 & 12 & mioquimia \\
\hline Parox.: 2 & 19 & nistagmo \\
\hline
\end{tabular}

período interictal nas regiões dos músculos periorbitários ou nas mãos e respodem ao uso de fenitoína.

O segundo tipo de ataxia paroxística (ACAD tipo 2) também pode se iniciar na infância e adolescência, com crises de maior duração da ataxia (horas ou dias), desencadeadas por estresse, e exercícios, e pode se associar à presença de nistagmo no período interictal. A doença foi recentemente associada a um locus mapeado no cromossoma 19 (sem causa ainda definida) e reponde ao tratamento com acetazolamida. Há que se ressaltar a proximidade do locus com o da enxaqueca hemiplégica familial e da doença definida como CADASIL $^{2,9,24}$.

\section{CONSIDERAÇÕES FINAIS}

As ataxias hereditárias autossômicas dominantes, agora melhor definidas como ataxias espinocerebelares (AEC), representam um grupo de enfermidades 
neurodegenerativas progressivas e incapacitantes, sem tratamento conhecido, e com grande heterogeneidade fenotípica e genotípica. A classificação clínico-genética permite uma melhor abordagem e estudo deste grupo de doenças. A tabela 5 resume as principais características clínicas/neurológicas e o locus genético dos principais tipos de AEC.

\section{SUMMARY}

The author make a revision about the autosomal dominant hereditary ataxias, now called spinocerebellar ataxias, the different kinds and a clinical-genetic classification are presented.

\section{KEYWORDS}

Hereditary ataxias, spinocerebellar ataxia, genetic locus.

\section{Referências}

1. Barbeau, A.; Roy, M.; Cunha, L. et al. The natural history of Machado-Joseph disease: analysis of 138 personally examined cases. Can J Neurol Sci, 11: 510, 1984.

2. Bressman, S.B. Genetics of Movement disorders: recent advances. In: Movement disorders. American Academy of Neurology, 48th Annual Meeting, São Francisco, 1996.

3. Cassa, E. Ataxia cerebelar autossômica dominante no Brasil: Análise de 270 anos de história e genealogia, incluindo a caracterização de uma grande familia com doença de Machado-Joseph. Tese de Doutorado, Ribeirão Preto, SP, 1996.

4. Coutinho, P.; Andrade, C. Autosomal dominant system degeneration in Portuguese families of the Azores Islands: a new genetic disorder involving cerebellar, pyramidal, extrapyamidal and spinal cord motor functions. Neurology, 28: 703,1978

5. Coutinho, P. Doença de Machado-Joseph. Tentativa de definição. Tese de Doutorado, Porto, Portugal, 1992.

6. Coutinho, P.; Silva, C.C.; Alves, C.; Barros,J.; Loureiro, J.L.; Guimarães, J. Variation in clinical expression of MJD with progression and age. Workshop Abstracts. 3rd International Workshop on Machado-Joseph Disease, Furnas, São Miguel, Azores, april, 1994

7. Dawson, D. M. Ataxia in families from the Azores. N. Engl.J. Med., 296: 1529, 1977.

8. Fowler, H.L. Machado-Joseph disease: a ten year study. Arch Neurol., 41: 921, 1984

9. Hammans, S.R. The inherited ataxias and the new genetics. J Neurol Neurosurg Psychiatry, 61: 327-332,1996.

10. Harding, A.E. The Hereditary Ataxias and Related Disorders. London, Churchill Livingstone, 1984.

11. Higgins, J.J.; Nee, L.E.; Vasconcelos, O.; Ide, S.E.; Ladevan, C.; Goldfarb, L.G.; Polymeropoulos. Mutations in american families with spinocerebellar ataxia (SCA) type 3: SCA 3 is allelic to Machado-Joseph disease. Neurology, 46: 208$213,1996$.

12. Junck, L.; Fink,J.K. Machado-Joseph disease and SCA 3 : The genotype meets the phenotypes. Neurology, 46: 4-8, 1996.

13. Lopes-Cendes, I.; Steiner,C.E.; Silveira, I.; Pinto Jr.,W.; Maciel, J.A.; Roleau, G.A. Clinical and molecular characteristics of a brazilian family with spinocerebellar ataxia type 1. Arq. Neuropsiquiatr, 54: 412-418,1996.

14. Lima, L.; Coutinho, P. Clinical criteria for diagnosis of Machado-Joseph disease: report of a non-azorean family. Neurology, 30: 31, 1980.
15. Nakano, K.K.; Dawson, D. M.; Spence, A. Machado-Joseph: a hereditary ataxia in Portuguese emigrants to Massachusetts. Neurology, 22: 49, 1972.

16. Nachmanoff, D.B.; Segal, R.A.; Dawson, D. M.; Brown, R.B.; De Girolami, U. Hereditary ataxia with sensory neuronopathy: Biemond ataxia. Neurology, 48: 273-275, 1997.

17. Orozco Dias, G.; Fleites, N.A.; Sagaz, C.R.; Auburger, G. Autossomal dominant cerebellar ataxia: Clinical analysis of 263 patients from a homogeneous population in Holguin, Cuba. Neurology, 40: 1369, 1990.

18. Radvany, J.; Avila, J.O.; Gabbai, A.A.; Bacheschi, L.A. Doença de Machado-Joseph: as duas primeiras familias relatadas no Brasil. Tema livre do $13^{\circ}$ Congresso Brasileiro de Neurologia. Arq. Neuro-Psiquiat (São Paulo), 46(S): 152, 1988.

19. Radvany, J.; Camargo, C.H.P.; Costa, Z.M.; Fonseca, N.C. Nascimento, E.D. Machado-Joseph disease of Azorean ancestry in Brasil : The Catarina kindred. Arq. Neuro-Psiquiat, (São Paulo) 51: 21, 1993.

20. Romanul, F.C.A.; Fowler, H.L.; Radvany, J.: Feldman, R.G. Feingold, M. Azorean disease of the nervous system. N. Engl. J. Med., 296: 1505,1977.

21. Rosemberg, R.N.; Nyhan, W. L.; Bay, C.; Shore, P. Autossomal dominant striatonigral degeneration: a clinical, pathologic and biochemical study of a new genetic disorder. Neurology, 26: 703, 1976.

22. Schols, L.; Amoiridis, G.; Epplen, J.T.; Langkafel, M.; Przuntek, $\mathrm{H}$.; Riess $\mathrm{O}$. Relations between genotype and phenotype in german patients with the Machado-Joseph disease mutation. J Neurol Neurosurg Psychiatry, 61: 466-470, 1996.

23. Silveira, I.; Lopes-Cendes, I.; Kish, S.; Maciel, P.; Gaspar,C.; Coutinho, P.; Botez, M.I.; Teive, H.; Arruda, W.; Steiner, C.E.; Pinto Jr., W.; Maciel, J.A.; Jain, S.; Sack, G.; Andermann, E.; Sudarsky, L.; Rosemberg, R.; MacLeod, P.; Chitayat, D.; Babul, R.; Sequeiros, J.; Roleau, G.A. Frequency of spinocerebellar ataxia type 1, dentatorubropallidoluysian atrophy, and Machado-Joseph disease mutations in a large group of spinocerebellar ataxia patients. Neurology, 46: 214-218, 1996.

24. Subramony, S.H. Hereditary Ataxias. In: Genetics in Neurology. American Academy of Neurology, 48th Annual Meeting, São Francisco, 1996.

25. Sudarsky, L.; Corwin, L.; Dawson, D.M. Machado-Joseph disease in New-England: Clinical description and distinction from the olivopontocerebellar atrophies. Movement Disorders, 7: 204, 1992.

26. Teive, H.A.G.; Arruda, W.O.; Trevisol-Bittencourt, P.C. Doença de Machado-Joseph. Descrição de cinco membros de uma familia. Arq. Neuro-Psiquiat, (São Paulo) 49: 172, 1991.

27. Teive, H.A.G.; Arruda, W.O.; Trevisol-Bittencourt, P.C. Ataxias cerebelares autossômicas dominantes, incluindo a doença de Machado-Joseph, no sul do Brasil: estudo de 44 pacientes. Arq. Neuro-Psiquiat, (São Paulo), P-292, 1991.

28. Wadia, N.H.; Swami, K. A new form of heredo-familial spinocerebellar degeneration with slow eye movements (nine families). Brain, 94: 359,1971.

29. Warner, T.T.; Williams, L.D.; Walker, R.W.H.; Flinter, F.; Robb, S.A.; Bundey, S.E.; Honavar, M.; Harding, A.E. A clinical and molecular genetic study of dentatorubropallidoluysian atrophy in four european families. Ann. Neurol., 37: 452-459, 1995.

30. Woods, B.T.; Schaumburg, H.H. nigro-spino-dentatal degeneration with nuclear ophthalmoplegia: a unique and partially treatable clinico-pathological entity. J. Neurol. Sci., 17: 149, 1972.

\section{Endereço para correspondência:}

Hélio Teive

Pça. Stos. Andrade, 37-A, Ap.112

80020-300 Curitiba (PR) 